\title{
Size matters : how height affects the health, happiness, and success of boys--and the men they become (/review/10.5860/CHOICE.44-6523)
}

Hall, Stephen S. (/search?exactauthor=Hall, Stephen S) Houghton Mifflin, 2006 388p, $0618470409 \$ 26.00,9780618470402 \$ 26.00$

LC Call Number: QP (/search?lcstart=QP)84

This is an impressive book by one of the finest popular social science writers. Hall offers a compelling demonstration that size--that is, one's height--does indeed matter, and in numerous, profound, and often-unexpected ways. He does not simply reiterate common assumptions about the consequences one's height has on social status, self-confidence, career success, and the like, although he does lay out chillingly strong evidence for these popular truisms. What sets this book apart from most socialscience trade books is the multifaceted, comprehensive, interdisciplinary information the author has mined about the topic. Hall's tour of the consequences of size takes the reader through developmental and social psychology, anthropology, ethology, medicine, biology, history, and art. He covers topics ranging from the long-term effects of low birth weight to the psychology and sociology of bullying to clinical treatments for physical growth. The book is written in the engaging, deceptively light style that one has come to expect from Hall, alternating between anecdotes and reviews of the pertinent research (detailed in extensive notes).

Summing Up: Essential. All readers; all levels.

Reviewer: R. Levine (/search?reviewer=R. Levine), California State University--Fresno Recommendation: Essential Readership Level: All Readership Levels, General Readers, Lower-division Undergraduates, Upperdivision Undergraduates, Graduate Students, Researchers/Faculty, Two-Year Technical Program Students, Professionals/Practitioners Interdisciplinary Subjects:

Subject: Social \& Behavioral Sciences - Psychology (/search?q=\&sbj[]=psy)

Choice Issue: jul 2007 vol. 44 no. 11

Choice Review \#: 44-6523 
Review DOI: 10.5860/CHOICE.44-6523 